\title{
A study of headaches and migraine in Sjögren's syndrome and other rheumatic disorders
}

\author{
B PAL ${ }^{1}$ C GIBSON ${ }^{2}$ J PASSMORE, ${ }^{1}$ I D GRIFFITHS,${ }^{1}$ \\ AND W C DICK
}

From the ${ }^{1}$ Department of Rheumatology, Royal Victoria Infirmary, Newcastle upon Tyne and the ${ }^{2}$ Department of Medical Physics, Dryburn Hospital, Durham

SUMMARY Migraine occurs with increased frequency in patients with systemic lupus erythemacos tosus and in subjects suffering from Raynaud's phenomenon without any underlying connective्己 tissue disorders. A possible link between migraine and Raynaud's phenomenon has beept suggested. Two rheumatic conditions where Raynaud's phenomenon occurs very commonly are scleroderma and primary Sjögren's syndrome. It is possible that migraine is also common in these. disorders but has been unrecognised. Therefore, the prevalence of migraine was assessed by 7 questionnaire in 191 subjects suffering from various connective tissue disorders and contro subjects. Migraine was diagnosed in 16/35 (46\%) patients with primary Sjögren's syndrome $\vec{p}$ $31 / 97(32 \%)$ patients with scleroderma, $4 / 33(12 \%)$ patients with rheumatoid arthritis/Sjögren syndrome compared with $3 / 26(11 \%)$ control subjects. A family history of headaches was more common in the patient groups than controls. There was a significant association betwee occurrence of Raynaud's phenomenon and migraine. Small vessel pathology may underlie bote migraine and Raynaud's phenomenon in these connective tissue disorders-as has bee

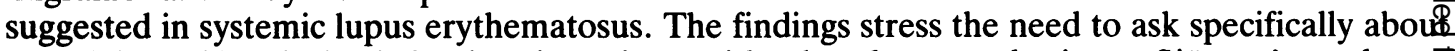
complaints of headaches/migraines in patients with scleroderma and primary Sjögren's syndrom $\vec{E}$ for the appropriate total management of these patients.

Key words: Raynaud's phenomenon, scleroderma.

Certain connective tissue disorders such as giant cell arteritis are characterised by headaches, while in others headaches may occur as unrelated events. An increased prevalence of classical migraine was found in 30 female patients with systemic lupus erythematosus (SLE) compared with an age and sex matched control group by means of a questionnaire survey. ${ }^{1}$ Patients with rheumatoid arthritis (RA) may complain of headaches, which may have varying pathogenic mechanisms. For example, subluxation in the upper cervical spine may cause pain in the upper neck radiating to the occipital or temporal regions, or may cause retro-orbital pain. ${ }^{2}$ Temporomandibular joint involvement in RA may also give rise to pain radiating to the temporal region. The possibility that patients with RA suffer from any other specific type of headache, as do many patients with SLE, has not been studied.

Accepted for publication 30 August 1988.

Correspondence to Dr B Pal, Department of Rheumatology, Room 17, Pavilion 10, Withington Hospital, Manchester M20 8LR.
Although Isenberg et al failed to find a correlatio between migraine and Raynaud's phenomenon im patients with SLE, ${ }^{1}$ a study demonstrating a signifio cant association between migraine and Raynaud's phenomenon in non-rheumatic patients has beer reported. ${ }^{3}$ One connective tissue disorder in which very high proportion of patients suffer fronf Raynaud's phenomenon is scleroderma/systemiô sclerosis. ${ }^{4}$ In view of the reportedly high prevalence of migraine in patients with SLE and the observarv tion that there is a close relation between Raynaud' $\delta$ phenomenon and migraine, Raynaud's phenom enon might have been unrecognised or unappreciate $\$$ in these patients in the presence of other pressing problems or dramatic clinical features. Patients with primary Sjögren's sydrome (primary SS) also como: monly suffer from Raynaud's phenomenon, ${ }^{5}$ but th ${ }^{\circ}$ question of migraine has not been considered in thi connective tissue disorder either.

The aim of the present study was to assess the prevalence of migraine in patients with primary $\mathrm{S} 8$ 
and scleroderma, and if the prevalence in these diseases was found to be increased to investigate a possible temporal relation between migraine and Raynaud's phenomenon.

\section{Patients and methods}

One hundred and ninety one patients belonging to the different categories of SS, scleroderma, and control subjects were studied. Primary SS was diagnosed in patients suffering from (a) dry/gritty eyes (keratoconjunctivitis sicca) diagnosed on the basis of an abnormal Schirmer's test with less than 5 $\mathrm{mm}$ moistening of Schirmer paper strips and abnormal ocular rose bengal staining and $(b)$ xerostomiaboth subjective and objective- on the basis of clinical examination (lack of saliva pool under the tongue) and reduced stimulated salivary flow rate (less than $1.45 \mathrm{ml} / \mathrm{min}$ ). ${ }^{6}$ None of the patients with primary SS had criteria which met the requirement for the diagnosis of another connective tissue disorder. Patients with RA/SS fulfilled the American Rheumatism Association criteria for definite or classical $\mathrm{RA}^{7}$ and had either keratoconjunctivitis sicca or xerostomia, or both, established by methods stated above.

All the patients with scleroderma were members of the Scleroderma Society within the United Kingdom and were given a definite diagnosis of scleroderma and treated as such by consultant rheumatologists. The control subjects were drawn from the hospital staff and were without any known medical or surgical problems. The questionnaire used in this study was a modification of the one used by Taylor et al. ${ }^{8}$ It consisted of 17 items about the frequency, severity, and nature of headaches and included three special questions about common accompaniments of migraine-namely, (a) some warning before the headache; $(b)$ associated nausea or vomiting; $(c)$ pain on one side of the head only. The word 'migraine' was not used in the questionnaire. The inquiry included any history of previous headaches. Migraine was considered to be present either when a throbbing headache, frequently unilateral, usually associated with nausea, vomiting, and photophobia, was preceded or accompanied by an aura of the visual, motor, or sensory type (classical) or when there was a history of throbbing headache, less often strictly unilateral, though often accompanied by nausea, vomiting, and photophobia but not preceded or accompanied by an aura (common). ${ }^{8}$

A family history of headache was also sought and questions were asked about previous or current use of any drug, including oral contraceptives and specific antimigrainous drugs.

An inquiry into Raynaud's phenomenon was based on a questionnaire modified from Miller et al as follows: $(a)$ Do you suffer from episodes when your fingers or toes turn white? (2 points); (b) Does the involved area become numb or throb? (2 points); $(c)$ Does the white area later turn blue or red? (1 point); (d) Are the episodes provoked by tobacco, cold, or emotion? (2 points).

According to this scoring system a diagnosis of Raynaud's phenomenon was made if the total score was four or more.

Patients were also questioned about the timing of the episodes of the Raynaud's phenomenon and headaches, if any, and whether there was any temporal relation between the two. The results were analysed by $\chi^{2}$ test.

\section{Results}

Migraine was diagnosed according to criteria described above. Patients with headache but without any migrainous accompaniment were considered to have non-migrainous headaches.

Headaches were complained of by 26 patients $(74 \%)$ in the group with primary SS, 11 patients $(33 \%)$ in the RA/SS group, 43 patients $(44 \%)$ in the scleroderma group, and 13 patients $(50 \%)$ in the normal control group (Table 1). Prevalence of headaches in the group with primary SS only was significantly different from that of the control group $(\mathrm{p}=0 \cdot 05)$.

On further analysis of patients who admitted to headaches, characteristics for migraine were fulfilled by the patients as follows: $16(46 \%)$ in the primary SS group, $4(12 \%)$ in the RA/SS group, 31 $(32 \%)$ in the scleroderma group, and $3(11 \%)$ in the control group (Table 1). Migraine was significantly more common in both primary SS $(p=0.01)$ and scleroderma $(p=0.05)$ than in the control group.

A past history of migraine was found in three patients in the scleroderma group and in one patient in each of the other three groups (Table 1).

Table 1 shows the frequencies with which migraine episodes occurred in the different categories of SS and other patients. It can be seen that patients in the primary SS and scleroderma groups, in particular, had more frequent migraine attacks than those in the other two groups.

Table 1 also shows the severity of the migraine in the different categories of patients. Again it is apparent that the more severe episodes of migraine occurred mainly in the primary SS and scleroderma groups.

A number of patients in each category did not answer the question about a family history of headaches, but a positive family history was found more frequently in the primary SS and scleroderma 
Table 1 Headaches and migraine in patients and control subjects

\begin{tabular}{|c|c|c|c|c|}
\hline Characteristics & $\begin{array}{l}\text { Primary } S S^{*} \\
(n=35)\end{array}$ & $\begin{array}{l}R A^{*} / S S \\
(n=33)\end{array}$ & $\begin{array}{l}\text { Scleroderma } \\
(n=97)\end{array}$ & $\begin{array}{l}\text { Normal } \\
\text { controls } \\
(n=26)\end{array}$ \\
\hline $\mathbf{M} / \mathbf{F}$ & $2 / 33$ & $1 / 32$ & $16 / 81$ & $4 / 22$ \\
\hline \multicolumn{5}{|l|}{ Age (years) } \\
\hline Mean (SD) & $55(11)$ & $62(8)$ & $50 \cdot 3(12 \cdot 6)$ & $45 \cdot 6(17 \cdot 5)$ \\
\hline Range & $34-75$ & $38-75$ & $23-77$ & $19-74$ \\
\hline \multicolumn{5}{|l|}{ Disease duration (years) } \\
\hline Mean (SD) & $9(7 \cdot 5)$ & $6 \cdot 5(5 \cdot 3)$ & $7 \cdot 8(6 \cdot 8)$ & - \\
\hline Range & $1-35$ & $1-30$ & $1-35$ & - \\
\hline No $(\%)$ had headaches & $\begin{array}{l}26(74) \\
(p=0 \cdot 05)\end{array}$ & $\begin{array}{l}11(33) \\
(p=N S)\end{array}$ & $\begin{array}{l}43(44) \\
(p=N S)\end{array}$ & $13(50)$ \\
\hline No (\%) had migraine & $\begin{array}{l}16(46) \\
(p=0 \cdot 01)\end{array}$ & $\begin{array}{l}4(12) \\
(p=N S)\end{array}$ & $\begin{array}{l}31(32) \\
(p=0.05)\end{array}$ & $3(11)$ \\
\hline Past history of migraine & 1 & 1 & 3 & 1 \\
\hline \multicolumn{5}{|l|}{ Frequency of migraine: } \\
\hline Several times a year & 3 & 1 & 10 & 0 \\
\hline About once a month & 2 & 0 & 9 & 1 \\
\hline Several times a month & 1 & 2 & 5 & 2 \\
\hline About once a week & 5 & 0 & 2 & 0 \\
\hline Several times a week & 5 & 1 & 5 & 0 \\
\hline \multicolumn{5}{|l|}{ Migraine severity: } \\
\hline Mild & 2 & 3 & 5 & 0 \\
\hline Moderate & 3 & 1 & 6 & 0 \\
\hline Severe & 5 & 0 & 11 & 2 \\
\hline Combination of above & 6 & 0 & 9 & 1 \\
\hline
\end{tabular}

*SS=Sjögren's syndrome; RA=rheumatoid arthritis.

Table 2 Prevalence of Raynaud's phenomenon and temporal relation with migraine

\begin{tabular}{|c|c|c|c|c|}
\hline Characteristic & $\begin{array}{l}\text { Primary } \\
(n=35)\end{array}$ & $\begin{array}{l}R A^{*} / S S \\
(n=33)\end{array}$ & $\begin{array}{l}\text { Scleroderma } \\
(n=97)\end{array}$ & $\begin{array}{l}\text { Normal } \\
\text { controls } \\
(n=26)\end{array}$ \\
\hline Raynaud's phenomenon (No (\%)) & $\begin{array}{l}18(51) \\
(p=0 \cdot 01)\end{array}$ & $\begin{array}{l}10(30) \\
(p=N S)\end{array}$ & $\begin{array}{l}86(89) \\
(p<0 \cdot 001)\end{array}$ & $4(15)$ \\
\hline $\begin{array}{l}\text { Temporal relation noted between } \\
\text { Raynaud's phenomenon and migraine (No (\%)) }\end{array}$ & $2(6)$ & 0 & $5(5)$ & 0 \\
\hline
\end{tabular}

*SS=Sjögren's syndrome; RA=rheumatoid arthritis.

groups than in the RA/SS group and the normal subjects.

Raynaud's phenomenon by the criteria detailed above was found, as expected, in most patients in the scleroderma group, where 86 patients $(89 \%)$ had relevant symptoms. A surprisingly high proportion of patients in the primary SS group (18 patients; $51 \%$ ) also admitted to Raynaud's phenomenon, while 10 patients $(30 \%)$ in the RA/SS group and four normal subjects (15\%) admitted to symptoms characteristic of Raynaud's phenomenon (Table 2).

Two patients in the group with primary SS and five in the scleroderma group admitted to an association between Raynaud's phenomenon and migraine, while none in the RA/SS group or normal control group noticed any such relation (Table 2). Table 3 gives the occurrence of migraine in patients with Raynaud's phenomenon. Statistical analysis showed that there was a significant association between the occurrence of Raynaud's phenomenor and migraine.

Table 3 Prevalence of migraine in patients* with Raynaud's phenomenon

\begin{tabular}{|c|c|c|}
\hline Patient group & $R P \dagger$ positive & $R P$ negative \\
\hline $\begin{array}{l}\text { (a) Migraine positive group } \\
\text { (b) Migraine negative group } \\
\text { (c) No headaches group }\end{array}$ & $\begin{array}{l}43 \\
18 \\
52\end{array}$ & $\begin{array}{r}8 \\
11 \\
31\end{array}$ \\
\hline
\end{tabular}

*Including only patients with primary Sjögren's syndrome, sclero derma, and rheumatoid arthritis/Sjögren's syndrome. $\dagger R P=$ Raynaud's phenomenon. Statistics $\chi^{2}$ method:

(a) compared with (b) $\mathrm{p}<0.05$.

(a) compared with (c) $\mathrm{p}<0 \cdot 01$.

(b) compared with (c) $p=N S$. 
An analysis of the drugs taken by the patients showed that most patients, particularly in the RA/SS and the primary SS groups, were taking analgesics or non-steroidal anti-inflammatory drugs, or both. It is noteworthy that $\beta$ blockers were not being taken by any of the patients, and a significant proportion of the patients with scleroderma $(21 \%)$ were taking vasodilators such as nifedipine, ketanserin, or others. Other vasodilators as well as specific antimigraine drugs had been prescribed only for the group of patients with scleroderma but not for the other groups. Oral contraceptive drugs were being taken by three patients in the scleroderma group but by none in the other groups.

\section{Discussion}

This study shows a significantly higher prevalence of migraine in patients with primary SS and scleroderma, than in the RA/SS and normal control groups. Migraine had not been sought specifically in these patient categories in the past. It may be that in the presence of other disabling symptoms and dramatic clinical manifestations, which may occur in patients with scleroderma in particular, complaints of headaches in these patients have been ignored or overlooked. In SLE claims that migraine occurs frequently ${ }^{10} 11$ have been confirmed by Isenberg $e t$ al by a questionnaire survey designed to pick out complaints of migraine. ${ }^{1}$ The relatively high prevalence of migraine in the normal population as well as in patients with SLE suggested the need for a controlled study in patients with primary SS and scleroderma to determine the significance of these previous observations. In the general population ${ }^{12}$ and in a previous survey a prevalence of $5 \%$ was found in the rheumatology outpatient population. ${ }^{13}$ The latter study, however, was uncontrolled.

It is noteworthy from the present survey that $50 \%$ of the control subjects and a third of the patients with RA/SS admitted to headaches, thus reflecting the common prevalence of non-specific headaches in the general population as referred to above. Only three $(11 \%)$ of the normal control group admitted to migraine, however, compared with the much higher prevalences in the patients with primary SS and scleroderma.

Raynaud's phenomenon was found, as expected in most patients with scleroderma but, surprisingly, also in over half the patients in the primary SS group. There was no significant association between the attacks of Raynaud's phenomenon and migraine, though it is noteworthy that over $5 \%$ of the patients in the primary SS and scleroderma groups admitted to a temporal relation, while none of the other two groups did so. It has been suggested that small vessel disease may reflect the clinical manifestations of SLE, including Raynaud's phenomenon, and may contribute to cerebrovascular dysfunction causing migraines. ${ }^{14} \mathrm{~A}$ similar mechanism may underlie the migraine in the patient groups studied in this survey-that is, primary SS and scleroderma groups, and needs to be studied.

The association of migraine with connective tissue disorders such as SLE, scleroderma, and primary SS may indicate a link between these disorders, for which there may be common pathogenetic mechanisms, and further work on this may shed some light on the aetiopathogenesis of these diseases. In support of such a link, in SLE at least, is the fact that migrainous phenomena have been noted to be commonly associated with disease exacerbation and to subside with a decrease in disease activity. ${ }^{13}$ Further support for this concept comes from the observations of these authors that corticosteroids were more effective in controlling the vascular headache and scotomata of some of their patients with SLE than were analgesics and conventional antimigraine treatment.

The headache phase of migraine is thought to arise as a result of dilatation and sterile inflammation around branches of the external carotid artery. ${ }^{14}$ Research has focused on the part played by vasoactive substances, such as serotonin and others-for example, bradykinin and prostaglandins, ${ }^{15}$ in the observed vascular responses of the intracranial and extracranial circulation in this condition. Similar phenomena may underlie vascular headaches in scleroderma and primary SS as has been suggested in patients with SLE. ${ }^{13}$ There may be a primary neurological basis for migraine, however, and the vascular phenomena may be secondary to neurological changes as argued by Blau. ${ }^{16}$

Because of the reported high prevalence of migraine in subjects with Raynaud's phenomenon ${ }^{3}$ in a non-rheumatic population we analysed the results to explore the possibility that such an association may exist in rheumatic patients with high prevalence of Raynaud's phenomenon as studied in this series. This study showed that such an association does exist in primary SS and scleroderma.

It is interesting to note that more family members of patients with primary SS and scleroderma suffered from headaches than family members of the other two groups, but it was not possible to ascertain from the questionnaire what proportion of these family members actually suffered from migraine.

A few remarks are necessary about the drugs taken by the patients in this survey. It is particularly noteworthy that $\beta$ blockers were conspicuously absent from the drug list in the patient groups; there was also no association between oral contraceptives 
and prevalence of migraine in either the patients with primary SS or scleroderma.

It might be argued that the increased prevalence of migraine found in the patients with primary SS and scleroderma in this survey is a non-specific result of the stress and emotional upheavals associated with the disease. The possibility remains, however, that migraine in primary SS and scleroderma may in part be due to the underlying disease process as in the case of SLE. In view of the findings of this study patients with primary SS and scleroderma should be asked specifically about headaches and, in particular, migrainous headaches as they may be additional disabilities for these patients. The reward of such specific inquiries lies in the availability of specific antimigrainous treatment, which these patients might otherwise be denied.

We wish to thank Miss Joanne Cartwright for typing the manuscript.

\section{References}

1 Isenberg D A, Meyrick-Thomas D, Snaith M L, McKeran R O, Royston J P. A study of migraine in systemic lupus erythematosus. Ann Rheum Dis 1982; 41: 30-2.

2 Scott J T, ed. Copeman's textbook of rheumatology. 5th ed. Edinburgh: Churchill Livingstone, 1978.

3 Zahavi I, Chagnac A, Hering R, Davidovich S, Kuritzky A. Prevalence of Raynaud's phenomenon in patients with migraine. Arch Intern Med 1984; 144: 742-4.
4 Masi A T, Medsger T A, Rodman G P, et al. Methods anc preliminary results of the scleroderma criteria cooperation: study of the American Rheumatism Association. Clin Rheum Dis 1979; 5: 27-48.

5 Alexander E L, Provost T T. Cutaneous manifestations of primary Sjögren's syndrome: a reflection of vasculitis anథ్ association with anti-Ro (SS-A) antibodies. $J$ Invest Dermatod 1983; 80: 386-91.

6 Whaley K, Williamson J, Chisholm D M, et al. Sjögren'尺 syndrome. 1. Sicca components. $Q J$ Med 1973; 166: 279-304 ص్

7 Ropes M W, Bennett G A, Cobb S, Jacox R, Jessar R A. Revision of diagnostic criteria for rheumatoid arthritis. BulD Rheum Dis 1958; 9: 175-6.

8 Taylor P J, Pocock S J, Hall S A, et al. Headaches and migraine in colour retouchers. Br J Ind Med 1970; 27: 364-7.

9 Miller D, Waters D D, Warnica W, Szlachcic J, Kreeft J⿳亠丷厂 Théroux $\mathrm{P}$. Is variant angina the coronary manifestation of a generalised vasospastic disorder? N Engl J Med 1981; 30400 763-6.

10 Friedman A P. Headache. In: Baker A B, Baker L M eds Clinical neurology. Hagerstown: Harper and Row, 1976: $27 \overrightarrow{\vec{N}}$

11 Hughes G R V. Central nervous system lupus-diagnosis and treatment. J Rheumatol 1980; 27: 405-11.

12 Waters W E. Review of previous surveys of headache and migraine. In: Waters W E, ed. The epidemiology of migraine Bracknell: Boehringer Ingelheim, 1979: 11-13.

13 Brandt K D, Lessell S. Migrainous phenomena in systemi lupus erythematosus. Arthritis Rheum 1978; 21: 7-16.

14 Dalessio D J. In: Bronica J J, ed. Advances in neurology. Vol $4 \oplus$ New York: Raven Press, 1974: 395-401.

15 Eadie M J, Tyrer J H. Biochemical neurology. Lancaster: MTP Press, 1983: 244-8.

16 Blau J N. New ideas on the pathophysiology of migraine. In Triger D R, ed. Advanced medicine. Vol 22. London: Ballièrẹ Tindall, 1986: 399-407. 